\title{
Open suturectomy management in craniosynostosis of bilateral coronal and metopic suture
}

\section{Marthinson Andrew Tombeng',}

I Wayan Niryana'

'Department of Neurosurgery, Faculty of Medicine Udayana University, Sanglah General Hospital, Bali, Indonesia
Cite this article:

Tombeng MA \& Niryana IW. Open Suturectomy Management in Craniosynostosis of Bilateral Coronal and Metopic Suture: a Case Report. Neurologico Spinale Medico Chirurgico. 202I.4(I): I5- I8. DOI:

I0.36444/nsmc.v4il. I 45

Corresponding author:

Marthinson Andrew Tombeng

Department of Neurosurgery, Faculty of Medicine Udayana University, Sanglah General Hospital, Bali, Indonesia

tombengma@gmail.com

\begin{abstract}
Craniosynostosis is a cranial deformation that is characterized by the premature fusion of one or more of the cranial sutures. Synostosis of multiple suture is a rare case and can be treated with open suturectomy procedure which is one of the surgical management by removing the fused suture with the purpose to allow the constricted area to expand with the growing brain. We present a case of a 2-month-old male infant with abnormal head shape since birth with a non-contrast 3D computed tomography (CT) scan of the head confirmed closure of the bilateral coronal and metopic suture. Open suturectomy was performed with no post operative complications. Open suturectomy technique can be performed in the management of multisutural craniosynostosis as indicated. The diagnosis of which suture are affected, the timing of surgery, and the prevention of surgical complication such as excessive blood loss are the important factors need to be considered.
\end{abstract}

Keywords: craniosynostosis, suturectomy, coronal, metopic

\section{Introduction}

Craniosynostosis is a craniofacial malformation that is characterized by the premature fusion of one or more of the cranial sutures that evolve during embryonic life and appear at birth. ${ }^{1-}$

${ }^{4}$ Its incidence is estimated to be 1 in 2,000-2,500 live births. ${ }^{1}$ The skull and the growing brain are restrained under the premature fusion of the cranial suture, leading to a compensatory expansion into regions of the skull that are not affected. ${ }^{5}$ This condition also will result in an abnormal head shape and increase intracranial pressure in one-third of all cases that may have a mental maldevelopment. ${ }^{6}$ Craniosynostosis is classified as isolated (fusion of only one suture) or complex (more than one suture fused). ${ }^{7}$ Isolated fusions are named by the involved suture, and the cranial shape takes on a characteristic dysmorphology. In 1851, Virchow ${ }^{8}$ described in his paper about the growth patterns of craniosynostosis, which is known as the Virchow's law. Virchow's law states that in craniosynostosis the skull growth is restricted to a plane perpendicular to the prematurely fused suture and is enhanced in a plane parallel to it. The shape of the head may become more complex when more than one sutures are involved. Craniosynostosis is also classified as syndromic or nonsyndromic. Syndromic craniosynostosis is defined as fusion of multiple sutures with associated extracranial extracranial anomalies. ${ }^{7}$ The frequency of syndromic craniosynostosis was reported 
between 0.4 and 1.0 per 1000 live births, which is less frequent than non-syndromic craniosynostosis. ${ }^{5}$

Craniosynostosis of more than one suture is a rare case and can be treated with open suturectomy procedure which is one of the surgical management by removing the fused suture with the purpose to allow the constricted area to expand with the growing brain.

\section{Case Report}

We present a case of a 2-month-old male infant with abnormal head shape (brachycephaly) (Figure 1) and a history of seizure 1 month prior to admission. The patient was born full term by cesarean section with birth weight of $3.55 \mathrm{~kg}$, birth length $50 \mathrm{~cm}$, and occipitofrontal circumference $37 \mathrm{~cm}$. The patient also has a history of neonatal asphyxia. Non-contrast 3D computed tomography (CT) scan of the head confirmed closure of the metopic and bilateral coronal suture (Figure 2).
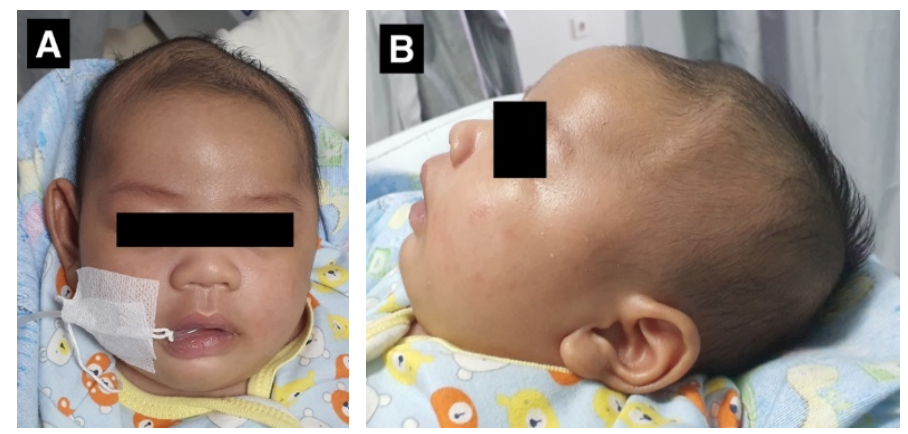

Figure 1. The abnormal head shape of the patient. Front view (A) and side view (B).
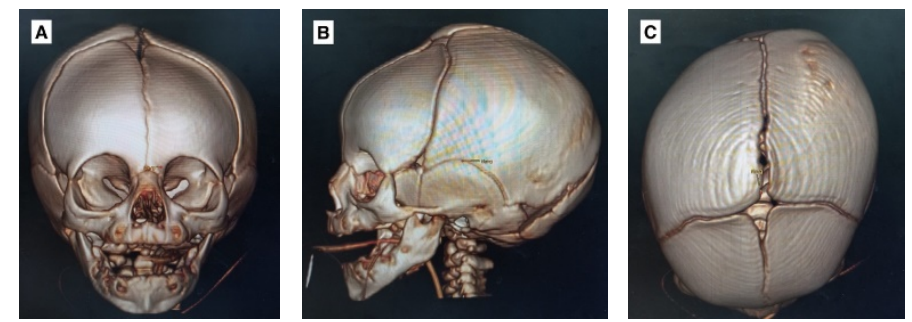

Figure 2. Bilateral coronal and metopic craniosynostosis. Front view (A), side view (B), and top view (C) of non-contrast 3D CT scan of the head showing closure of the metopic and bilateral coronal suture.

Open suturectomy was undertaken at the age of 10 weeks. The patient's head was placed in a neutral supine position. The head was shaved at the surgical area and was prepared using Chlorhexidine soap followed by disinfection using povidone iodine solution after a single bolus of antibiotics was given. The frontal cranial was exposed through bicoronal skin incision. Four burr holes were done, 1 at the keyhole for each side, and 2 others were done at the coronal suture for each side. A 2-3 cm wide suturectomy was performed along the closed bilateral coronal suture across the anterior fontanel and the mectopic suture (Figure 3) using Kerrison rongeurs and bone rongeurs. The bleeding from the bone was controlled by wax. There were no complication after surgery.
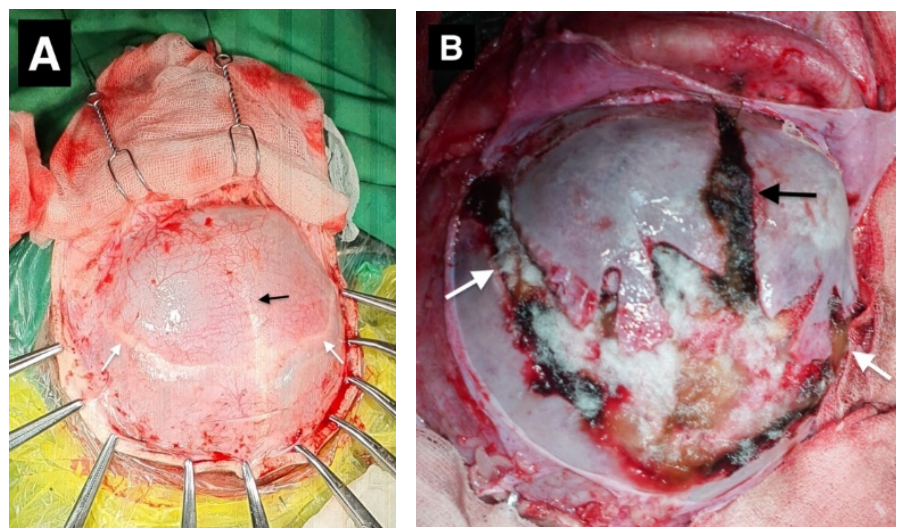

Figure 3. Open suturectomy of bilateral coronal and metopic craniosynostosis. Fusion of bilateral coronal and metopic suture (A) and post suturectomy procedure (B). White arrow (coronal suture), black arrow (metopic suture).

\section{Discussion}

Craniosynostosis of bilateral coronal and metopic suture is a rare case. The percentage of affected sutures are sagittal (40-55\%), coronal (20-25\%), metopic (5-15\%), and lambdoid (0-5\%). Craniosysnostosis with more than one suture affected, approximately $5-15 \%$ of cases. ${ }^{9}$

The diagnosis of craniosynostosis can be made based on physical examination, craniometrics measuring, and observation of the skull deformity that accompanies each type of suture fusion. The radiological examination also has an important role in the confirmation of the diagnosis, the surgical planning, and even the postoperative follow-up. ${ }^{7,10}$ In infants, an important consideration is that the use of radiation or the need of sedation/anesthesia increase the problem and must be reduced to minimum to prevent from their adverse effects. ${ }^{10}$

In this case the patient has a brachycephaly, which is most commonly the result of premature synostosis of both coronal sutures. Bilateral coronal craniosynostosis causes a short (anteroposterior) and wide (transverse) head. The anterior fontanel may be open or closed ${ }^{2,9}$, which in this case the anterior fontanel of the patient is closed. We also performed a non-contrast 3D head CT scan for confirmation of the diagnosis and surgical planning, which reveals premature synostosis of both coronal and metopic sutures. The high-resolution CT scan with 3D 
reconstruction is considered the gold standard in the radiological examination of craniosynostosis and must be carefully evaluated due to the radiation effect. Other radiological examination that can be used such as $\mathrm{x}$-ray, ultrasound and magnetic resonance imaging (MRI). Xrays are a fast and low-radiation diagnostic tool with a high specificity but low sensitivity in detecting complex and minor sutural synostoses. Ultrasounds can be useful because of the fastness of the execution, the absence of ionizing rays, and the possibility without using sedation, but very dependent on the operator's skill and suitable only for certain age periode. MRI eliminates the risks of ionizing radiation, but the requirement for the baby to keep the position in a long exam generally requires general anesthesia or sedation which become a major concern due to the related risks. ${ }^{10}$

Surgical management of craniosynostosis has developed significantly over the years. The first procedure reported for craniosynostosis is strip craniectomies or suturectomy. ${ }^{11}$ The purpose was to allow the constricted area to expand with the growing brain by removing the fused suture. Cranial vault reconstructions were introduced, to make a normal head shape with removing cranial bone, reshaping it, and stabilizing repositioned bony segment. ${ }^{12,13}$ This procedure has an excellent result but is a long-time surgical procedure with increased blood loss ${ }^{12}$ and prolonged time under anesthesia ${ }^{9}$. Less invasive surgical procedures have been developed with new techniques and applications to achieve the same outcomes and with an advantage of less blood loss and shorter scars ${ }^{12}$, but very much depends on the skills of the surgeon and the availability of the endoscopic instrument. The goal of surgical management in craniosynostosis is to correct the abnormal head shape of the cranial deformity and to prevent elevated intracranial pressure and other negative impacts on neurocognitive development and vision impairment. 5,7,12,13

The timing of surgical management depends on several factors such as the type and severity of synostosis, surgical technique, comorbidities, and surgeon preference. ${ }^{5,6,12}$ In the literature the optimal timing of surgery is 3 to 6 months of age. ${ }^{6}$ Some authors also divided the timing of surgery into early surgical intervention which occurs between 2 to 3 months of age and later surgical intervention occurs 6 to 12 months old. Early intervention has advantage of early decompression of elevated intracranial pressure and increase the intracranial volume to allow the brain to grow. ${ }^{5,12}$ The procedure can be less extensive, less invasive and has the better outcome if the age of the patient younger at the time of operation. However, it is important to consider that in infants even small amount of blood loss may cause significant impact due to very small blood volume and low hematocrit level. ${ }^{14}$ Later intervention allows remodeling easier as the bones are better developed, easier to reconstruct and to stabilize, and also the child has a greater total blood volume. ${ }^{15}$

The management of craniosynostosis, requires a multidisciplinary team approach. Neurosurgeon will work together with anesthesiologist, pediatrician, geneticist and other specialists during the course of diagnosis, treatment, and follow-up. ${ }^{5}$

\section{Conclusion}

Surgical management of craniosynostosis has developed significantly over the years. However, open suturectomy technique can be performed in the management of craniosynostosis of more than one suture as indicated, especially if there are limited resources to perform other surgical techniques such as endoscopic suturectomy. Special attention is needed to prevent excessive blood loss that can lead to postoperative complications.

\section{Acknowledgment}

No acknowledgment

\section{References}

1. Di Rocco F, Arnaud E, Renier D. Evolution in the frequency of nonsyndromic craniosynostosis: Clinical article. J Neurosurg Pediatr. 2009;4(1):21-25. doi:10.3171/2009.3.PEDS08355

2. Governale LS. Craniosynostosis. Pediatr Neurol. 2015;53(5):394-401. doi:10.1016/j.pediatrneurol.2015.07.006

3. Nagaraja S, Anslow P, Winter B. Craniosynostosis. Clin Radiol. 2013;68(3):284-292. doi:10.1016/j.crad.2012.07.005

4. Ursitti F, Fadda T, Papetti L, et al. Evaluation and management of nonsyndromic craniosynostosis. Acta Paediatr Int $J$ Paediatr. 2011;100(9):1185-1194. doi:10.1111/j.1651-2227.2011.02299.x

5. Tahiri Y, Bartlett SP, Gilardino MS. Evidence-Based Medicine: Nonsyndromic Craniosynostosis. Plast Reconstr Surg. 2017;140(1):177e-191e. doi:10.1097/PRS.0000000000003473

6. Kyutoku S, Inagaki T. Review of past reports and current concepts of surgical management for craniosynostosis. Neurol Med Chir (Tokyo). 2017;57(5):217-224. doi:10.2176/nmc.ra.2017-0006

7. Morris L. Management of Craniosynostosis. Facial Plast Surg. 2016;32(2):123-132. doi:10.1055/s-0036-1582228

8. Virchow R. Uber den Cretinismus, namentlich in Franken, und uber pathologische Schadelformen. Verh Phys Med Gesell Wurzbg. 1851;2:230-271.

9. Okada H, Gosain AK. Current approaches to management of nonsyndromic craniosynostosis. Curr Opin Otolaryngol Head Neck 
Surg. 2012;20(4):310-317. doi:10.1097/MOO.0b013e328355a869

10. Massimi L, Bianchi F, Frassanito P, Calandrelli R, Tamburrini G, Caldarelli M. Imaging in craniosynostosis: when and what? Child's Nerv Syst. 2019;35(11):2055-2069. doi:10.1007/s00381-019-04278-x

11. Mehta VA, Bettegowda C, Jallo GI, Ahn ES. The evolution of surgical management for craniosynostosis. Neurosurg Focus. 2010;29(6):1-7. doi:10.3171/2010.9.FOCUS10204

12. Morris LM. Nonsyndromic Craniosynostosis and Deformational Head Shape Disorders. Facial Plast Surg Clin North Am. 2016;24(4):517530. doi:10.1016/j.fsc.2016.06.007
13. Melin AA, Moffitt J, Hopkins DC, et al. Is Less Actually More? An Evaluation of Surgical Outcomes Between Endoscopic Suturectomy and Open Cranial Vault Remodeling for Craniosynostosis. J Craniofac Surg. 2020;31(4):924-926. doi:10.1097/SCS.0000000000006152

14. Barone CM, Jimenez DF. Endoscopic craniectomy for early correction of craniosynostosis. Plast Reconstr Surg. 1999;104(7):1965-1973. doi:10.1097/00006534-199912000-00003

15. Jeyaraj P. A Modified Approach to Surgical Correction of Anterior Plagiocephaly. J Maxillofac Oral Surg. 2012;11(3):358-363. doi:10.1007/s12663-011-0309-7

Articles published online under this model are officially published and can be cited and quoted using the DOI as the reference source. Neurologico [I] Spinale Medico Chirurgico has a policy that changes will not be made after publication of an article without following accepted procedures for making corrections to the scientific record. The entire contents of the Neurologico Spinale Medico Chirurgico are licensed under the Creative Commons Attribution 4.0 International License. You are free to share - copy \& redistribute the material in any medium or format, adapt - remix, transform, and build upon the material for any purpose, even commercially. Under the following terms, you must give appropriate credit, provide link to the license, and indicate if changes were made. You may do so in any reasonable manner, but not in any way that suggests the licensor endorses you or your use. 